\title{
OS MODOS DE SOCIABILIDADE CARIOCA DURANTE A VISITA CHILENA EM FINS DO OITOCENTOS
}

\author{
MALERBA, Jurandir; HEYNEMAN, Cláudia Beatriz; RAINHO, Maria do \\ Carmo Teixeira. Festas Chilenas. Sociabilidade e política no Rio de \\ Janeiro no Ocaso do Império. Porto Alegre: EDIPUCRS, 2014.
}

\section{Resenha}

Entre 09 de outubro e 19 de dezembro de 1889, o Brasil recebeu a visita diplomática chilena a bordo do encouraçado Almirante Cochrane. Este fato, além de ter causado um grande alvoroço político, econômico, social e cultural no país, e em especial na cidade do Rio de Janeiro, coincidiu com a transição do regime político imperial para república.

Atentos aos espaços visitados pelos chilenos, às comidas e bebidas servidas/degustadas, à programação destinada aos ilustres hóspedes, às práticas desportivas praticadas em sua homenagem, aos sons, bailes, músicas que deram o tom cordial entre os dois países, e toda a indumentária que acolheu os convidados, os organizadores de "Festas Chilenas. Sociabilidade e política no Rio de Janeiro no Ocaso do Império" - Jurandir Malerba, Cláudia B. Heyneman e Maria C. T. Rainho - tiveram a felicidade de reunir em oito capítulos, os diversos modos de sociabilidade existentes na cidade do Rio de Janeiro durante estes dois meses.

No primeiro capítulo, "As Festas Chilenas, A monarquia e a República", Jurandir Malerba apresentou inicialmente a mobilização monárquica brasileira na recepção cordial e diplomática da república chilena. Para isso, foi exposto o cenário carioca, as pessoas que ali viviam, inclusive o rei e seus fidalgos, bem como seus discursos e práticas rotineiras. Toda esta mobilização foi vista como excessiva por parte da imprensa, que aproveitou da situação para ironizar e criticar a situação política enfrentada pelo império e seu monarca em fins do século XIX.

Neste entremeio, Malerba observou o longo período (1852-1889) em que D. Pedro II esteve alheio à vida social, e às festividades dadas pela corte, questionando os 
motivos que teriam levado o imperador a autorizar uma festa de tamanha pompa aos chilenos.

Diferente da hipótese que considerava o baile na Ilha Fiscal em 09 de novembro de 1889 como uma forma de resistência política aos propagadores da república, ou mesmo como uma manobra de aliança chilena ante os republicanos, o autor entendeu o baile como o momento de despedida de seu reinado, uma vez que o imperador "já tinha em mente" o que lhe aguardava.

Concluindo sua análise, Malerba utilizou o romance Esaú e Jacó, de Machado de Assis e o quadro O Último Baile da Ilha Fiscal, de Aurélio de Figueiredo para analisar a rememoração daquele episódio e assinalar a certeza de que o terceiro reinado não passava apenas de uma ilusão.

Na sequência, Cláudia Beatriz Heynemann em "Souvenirs tropicais", focou a paisagem urbana e tropical, a relação conflituosa entre a natureza e civilização, e a necessidade de um planejamento que possibilitasse o apaziguamento de tais espaços.

Diante dos relatos de viagens, foram expostos os lugares frequentados pelos cariocas e pelos chilenos durante sua visita ao país, indicando o roteiro turístico daquela época, além dos espaços de sociabilidade vivenciados em tempos de império.

A carência de arborização e ajardinamento levou a mobilização de algumas reformas na segunda metade do século XIX. Além disso, houve melhorias em 1850, como o calçamento nas ruas, a construção de um cais em praias e a plantação de árvores, minimizando o distanciamento entre a natureza e a cidade. Mas apesar destas melhorias, a autora salientou um sentimento de incompletude diante dos projetos voltados para uma nova nação.

Dando continuidade ao panorama sócio-cultural existente na cidade do Rio de Janeiro durante o século XIX, Vivien Ishaq, em “O Rio de Janeiro das Festas Chilenas", identificou as habitações urbanas, freguesias rurais e as residências com iluminação a gás e bondes nas ruas Gonçalves Dias e do Ouvidor. Para a autora, o crescimento populacional e as melhorias sociais eram sinônimos de desenvolvimento, e de maior distinção social, visto que a cidade no limiar oitocentista, contava com mais de 100 mil escravos, e os meios de transporte instalados simbolizavam a separação entre o centro e a periferia.

Esta separação foi assimilada nas regiões da cidade, visto que a população pobre se amontoava em cortiços e habitações coletivas nas freguesias, enquanto os grandes latifundiários se instalavam na zona sul do Rio de Janeiro. 
Ishaq também constatou a influência francesa nos gostos e nos costumes. A Rua do Ouvidor, por exemplo, era vista como o ponto de encontro do modo europeu de se viver. Tão sublime e importante, em 1829 ela recebeu calçamento, sendo a primeira a contar com iluminação a gás na década de 60, e em 1862 se destacou por suas 205 lojas, sendo 91 estabelecimentos de franceses.

Além da rua, os espaços de sociabilidade começaram a ser mais frequentados, enquanto os eventos religiosos perderam terreno. Os salões, os teatros, os bailes públicos e privados, as corridas de cavalos e demais eventos itinerantes que percorriam a cidade também indicavam a distinção social perante outros grupos que não tinham a mesma oportunidade de frequentá-los. Neste contexto foi nítida a disputa da atenção chilena entre alguns clubes. Afinal, a presença estrangeira ou imperial nestes espaços renderia maior frequência perante a sociedade carioca.

Uma vez que a permanência chilena no Brasil fora regada por festas, concertos, homenagens, pompa e ostentação, notamos que a impressão deixada aos convidados não foi aquela existente no cotidiano do carioca. Tanta pompa e ostentação durante os dois meses de estadia chilena, não passou batida aos "Ácidos e venenos das Festas Chilenas", registrados pela imprensa da época, e por Sebastião Uchoa Leite no quarto capítulo.

Dentre os trinta e seis artigos escritos sobre o evento, o autor identificou apenas um com a assinatura e alguns utilizando pseudônimos, o que levou a crer que as críticas destiladas eram destinadas ao governo, e não necessariamente a presença chilena. Além disso, a única assinatura e os poucos pseudônimos revelaram a cautela em relação às autoridades oficiais devido ao contexto político da época. Deste modo, Leite identificou o uso de humor, sátira e chacota para driblar as possíveis censuras que pudessem surgir diante daquilo que queria ser dito através da imprensa. Assim, os textos ácidos e venenosos destilados nos impressos contemplaram personagens políticos, os "penetras" do baile, a guarda nacional, e os gastos excessivos feitos para alegrar os convidados.

Com isso, a imprensa através do humor acrimonioso, soube expressar em suas linhas e páginas o quão latente soou aos cofres públicos e aos não partícipes do baile na Ilha Fiscal a importância da presença chilena ao país.

Menos ácida foram “As práticas esportivas nas homenagens aos chilenos”, na qual Victor Andrade de Melo demonstrou através do desporte, a hospitalidade com que foram bem recebidos no Brasil. 
Para esse autor, a boa recepção feita pelos chilenos ao neto de D. Pedro II, Augusto Leopoldo de Saxe-Coburgo e Bragança, quando estivera em seu país, no ano de 1889, os interesses geopolíticos da América do Sul e os problemas econômicos vividos pelo Brasil, foram alguns dos motivos que justificaram o acolhimento caloroso aos chilenos.

Melo destacou os espaços de sociabilidade existentes que foram utilizados para recepção dos chilenos: circos com espetáculos equestres, ginásticos e acrobáticos; e práticas esportivas diversas, destacando o turfe e o remo.

Desde meados do século XIX, ambos os esportes foram se solidificando no Rio de Janeiro e caindo no gosto da população, que se divertia e buscava angariar algum trocado com as apostas. Já a elite participava com o intuito de angariar status social ao estabelecer relações com os membros da corte, além da distinção social diante de outros grupos.

As duas modalidades dividiam as elites, sendo que os grupos urbanos estavam mais alinhados ao remo, tido como símbolo de progresso e ligados à república, enquanto a elite agrária mantinha uma relação maior com o turfe, relacionada à monarquia, e considerado pelos primeiros como signo de atraso.

No caso do remo, apesar de se consolidar tardiamente em comparação ao turfe, ganhou o gosto carioca diante do crescimento populacional ocupando as praias, com intuito terapêutico e de entretenimento.

Não restritos aos espaços públicos, os clubes desportivos também promoveram bailes e concertos aos chilenos, demarcando as distinções sociais existentes no Rio de Janeiro, além de buscarem ganhar status e visibilidade da presença chilena e brasileira em seus eventos.

Nestas cerimônias, Carlos Sandroni nos revelou "Quem animou o Baile". Geralmente dominada pelas bandas militares, a música manteve um tom marcial. Porém, entre certos eventos, também foram executadas músicas indígenas, quadrilhas, valsas, polcas, lanceiros, óperas, operetas e o hino chileno e brasileiro.

Com a função de prestar solenidade, dançar e animar os convidados, a música também serviu como peça decorativa para ser ouvida. Dentre as melodias que se destacaram, estava a composição de Francisco Braga, intitulada Hino Chile-Brasil, mesclando trechos dos hinos de ambos os países e a polca Maria Bannen, composta por Antônio Santos, em homenagem à esposa do comandante chileno Constantino Bannen. 
E enquanto a música era executada, os convidados se serviam do diversificado menu oferecido pela corte. Em "O império a mesa", Laurent Suaudeau e Carlos Augosto Silva Ditadi deram atenção aos alimentos e às bebidas presentes durante a estada chilena no Brasil em 1889.

É interessante observar que os pratos servidos geralmente vinham escritos em francês, demonstrando uma aproximação com a gastronomia desse país. Os hábitos alimentares brasileiros foram se modificando desde a chegada da família real, possibilitando a vinda de novos produtos assimilados aos poucos em nossa culinária.

Atentos ao baile fiscal, o preparo de tais iguarias foi possível devido à infraestrutura existente na cidade, desde restaurantes, cafés e hotéis que se organizaram para atender a todos os gostos.

A imprensa não poupou comentários para destacar os excessos existentes, a má educação dos garçons no atendimento aos convidados do baile na Ilha Fiscal e a falta de pratos ditos "nacionais".

Uma das novidades e atrações gastronômicas foram os sanduíches, derivação inglesa das entradas: fatias de pão com pastas ou queijos. Já as frutas, apesar de não serem mencionadas, estiveram presentes nos sorvetes e nos sucos oferecidos ao longo da festa.

Sobre as bebidas servidas, eram comuns no país os vinhos oriundos de Portugal, porém diante da suntuosidade festiva, os vinhos franceses também tomaram o gosto dos convidados. Dentre as informações da época, cerca de 10 mil litros de cerveja e 304 caixas de bebidas foram utilizadas, equivalendo a mais de três mil garrafas. Pela conta da Casa Paschoal houve 11 tipos de pratos quentes, 15 de pratos frios, 12 tipos de sobremesa, 12 mil taças de sorvete e 20 mil sanduíches.

Tal luxuosidade nas festas e elegância nos pratos, também exigiu um bom trajar para receber os convidados. Em "A roupa e a moda nas Festas Chilenas", Maria do Carmo Teixeira Rainho completou o oitavo capítulo dando um panorama geral sobre as indumentárias utilizadas pelos brasileiros em fins do século XIX. Conforme destacou em seu artigo, a partir da segunda metade do século XIX a moda foi elevada à categoria de classe, ditando através de normas e jornais femininos, como se trajar em determinados espaços e eventos.

As mudanças sociais e os novos espaços de lazer ditavam novas indumentárias que foram introjetadas e assimiladas no país. Para isso, era necessário dominar os padrões de civilidade e etiqueta que foram publicados nos manuais, buscando uma 
aproximação com o padrão europeu e se distanciando das outras classes. Assim, o baile na Ilha Fiscal foi o momento oportuno para aplicar tais normais, ser bem visto e, se possível, ser bem comentado nos jornais.

No caso das mulheres, sua indumentária tinha a função de definir seu status social, bem como o poder pecuniário do pai, marido ou amante. Para atendê-las no dia do baile, a rua do Ouvidor, conhecida por seus famosos salões, ficou tumultuada, seja pelas senhoras e senhores a procura de trajes, perucas, jóias, cortes e preparos estéticos, seja pelo recebimento de materiais para atender toda esta demanda.

Enquanto os homens estavam restritos à moda, uma vez que já estavam casados, os mais jovens podiam dar uma atenção um pouco maior, sem sobressair aos padrões da época. No caso das mulheres era o contrário. Enquanto as solteiras ficavam restritas à moda, destinadas a uma estética serena, recatada e leve, as senhoras podiam ostentar de toda pompa e luxo fornecido por seu esposo.

A imprensa também estava atenta ao trajar dos convidados, publicando comentários ácidos e satíricos. Um jornalista do Correio do Povo descreveu que o desconhecimento das regras de civilidade caracterizava quem era "penetra" na festa.

Outros jornais destacaram aqueles que não tiravam o chapéu para conversar com as damas durante o baile, a guarda nacional com sua falta de civilidade ao andar de capacete e espada nos salões, ou então dos objetos perdidos ou esquecidos após o baile, dentre eles vários coletes femininos.

Isso nos leva a crer que as indumentárias não serviam apenas para ostentar o luxo, mas também para seduzir e tornar visível aquilo que não podia ser visto. Assim, as roupas, comidas e bebidas, músicas, atividades esportivas, os convidados, o contexto social, político, econômico e cultural não passaram despercebidos pela imprensa do período, nem pelos autores do livro "Festas Chilenas".

Certamente a presença chilena no Brasil, deixou clara a amistosa relação diplomática entre ambos os países, a mobilização feita pela corte para receber seus convidados e passar a imagem de um país amistoso, organizado, limpo e bonito. Ainda que esta imagem tenha sido levada pelos chilenos, a imprensa da época e os autores não deixaram de expor tais disparidades e a verdadeira realidade brasileira.

Por fim, "Festas Chilenas" é um livro que contribui significativamente ao dar visibilidade aos modos de sociabilidade e práticas sócio-culturais existentes na cidade do Rio de Janeiro em fins do XIX. Em meio à transição do regime político do Império para a República, foi possível enxergarmos neste entremeio, como a sociedade carioca 
viveu, o que ela vestiu, comeu e ouviu. Acima de tudo, as festas chilenas possibilitaram entender que, dentre as rupturas e permanências, a impressão deixada, foi a de um país que, apesar dos percalços, soube acolher bem seus visitantes.

\section{Everton Vieira Barbosa}

Mestrando em História pela UNESP - Campus de Assis. Bolsista FAPESP semusico@hotmail.com

DOI: 10.12957/intellectus.2016.21681 